\title{
(D) Acute Myocarditis Mimicking an Acute Coronary Check for updates Syndrome: Case Report and Mini-Review of the Literature
}

\begin{tabular}{|c|c|}
\hline & $\begin{array}{l}\text { Fatima Ezzahraa Talhi }{ }^{1,} \text {, Monia Elmourid }{ }^{1} \text {, Anass Maaroufi }{ }^{1} \text {, } \\
\text { Zakaria Qechchar }^{1} \text {, Salim Arous }{ }^{1} \text {, El Ghali Bennouna }{ }^{1} \text {, Leila Azzouzi }{ }^{1} \text {, } \\
\text { Rachida Habbal }^{1}\end{array}$ \\
\hline DOI: $10.29252 /$ ijcp-27070 & $\begin{array}{l}{ }^{1} \text { Cardiology Department, University Hospital Ibn Rochd, Casablanca, Morocco } \\
{ }^{*} \text { Corresponding author: Fatima Ezzahraa Talhi, Cardiology Department, University } \\
\text { Hospital Ibn Rochd, Casablanca, Morocco.E-mail:dr.f.talhi@gmail.com }\end{array}$ \\
\hline $\begin{array}{l}\text { Submitted: } 13-09-2019 \\
\text { Accepted: 07-11-2019 }\end{array}$ & \multirow{3}{*}{$\begin{array}{l}\text { Abstract } \\
\text { Acute myocarditis is often a challenging diagnosis due to a lack of specific clinical or } \\
\text { paraclinical signs. It can be presented by a severe chest pain and localized ST elevation } \\
\text { on Electrocardiogram, in rare cases, misleading the diagnosis towards acute coronary } \\
\text { syndrome. After routine coronary angiography, a cardiac magnetic resonance imaging } \\
\text { is imposed to correct the diagnosis towards acute myocarditis. We report the } \\
\text { observation of a } 19 \text { year-old Moroccan male admitted to the cardiology department of } \\
\text { IBN ROCHD University hospital of Casablanca, for acute myocarditis misdiagnosed } \\
\text { initially as an acute myocardial infarction ST elevation and confirmed by cardiac } \\
\text { magnetic resonance imaging. }\end{array}$} \\
\hline $\begin{array}{l}\text { Keywords: } \\
\text { Acute Myocarditis } \\
\text { Acute Coronary Syndrome } \\
\text { Cardiac Magnetic } \\
\text { Resonance Imaging }\end{array}$ & \\
\hline $\begin{array}{l}\text { (C) 2020. International Journal } \\
\text { of Cardiovascular Practice. }\end{array}$ & \\
\hline
\end{tabular}

\section{INTRODUCTION}

Acute myocarditis is an inflammation of the heart muscle, confirmed histologically by a rate of inflammatory cells and signs of myocardial necrosis of non-ischemic origin [1].

Inaugural signs of heart failure, in the absence of coronary disease or progressive valvular disease stigma, should lead to the diagnosis of acute myocarditis, even more in the presence of flu symptoms during the previous days [2].

The diagnosis could be challenging, based on clinical presentation, confirmed mainly by cardiac magnetic resonance imaging (MRI) rarely by myocardial biopsy. We report the observation of a 19-year-old male admitted to the cardiology department of IBN ROCHD University Hospital of Casablanca, Morocco for acute myocarditis misdiagnosed initially as an acute myocardial infarction ST elevation (STEMI).

\section{CASE PRESENTATION}

It is about a 19-year-old male, without any cardiovascular risk factor but with a history of a flu-like signs, who was admitted to the intensive unit care for acute onset of constrictive retrosternal chest pain, persisting for the last 10 hours before admission.
The initial clinical examination revealed a blood pressure of 115/65 $\mathrm{mmHg}$, a Heart rate of $72 \mathrm{bpm}$ and body temperature of $38.3{ }^{\circ} \mathrm{C}$. The cardiac and pulmonary examination was normal-without signs of acute heart failure.

The electrocardiogram (ECG) showed an STsegment elevation in leads in the inferior territory (Fig 1). A chest X-ray was ordered with no abnormalities. Initial blood analysis showed a significantly elevated level of Troponin Ic up to 10 $\mathrm{ng} / \mathrm{ml}$. The echocardiography revealed left ventricular systolic dysfunction with hypokinesia localized in the inferoseptal wall, with an ejection fraction mildly reduced of $50 \%$, without any valvular abnormalities or pulmonary hypertension.

The patient received dual antiplatelet therapy, low molecular weight heparin and was admitted directly to the cath lab where an angiography showed the absence of coronary artery disease or spasm.

Biology tests showed inflammatory syndrome with a sedimentation rate of $100 \mathrm{~mm}$ and C-Reactive Protein up to $130 \mathrm{mg} / \mathrm{l}$ with high Creatine PhosphoKinase levels of $512 \mathrm{UI} / \mathrm{l}$. Viral serologies, however, were negatives. 


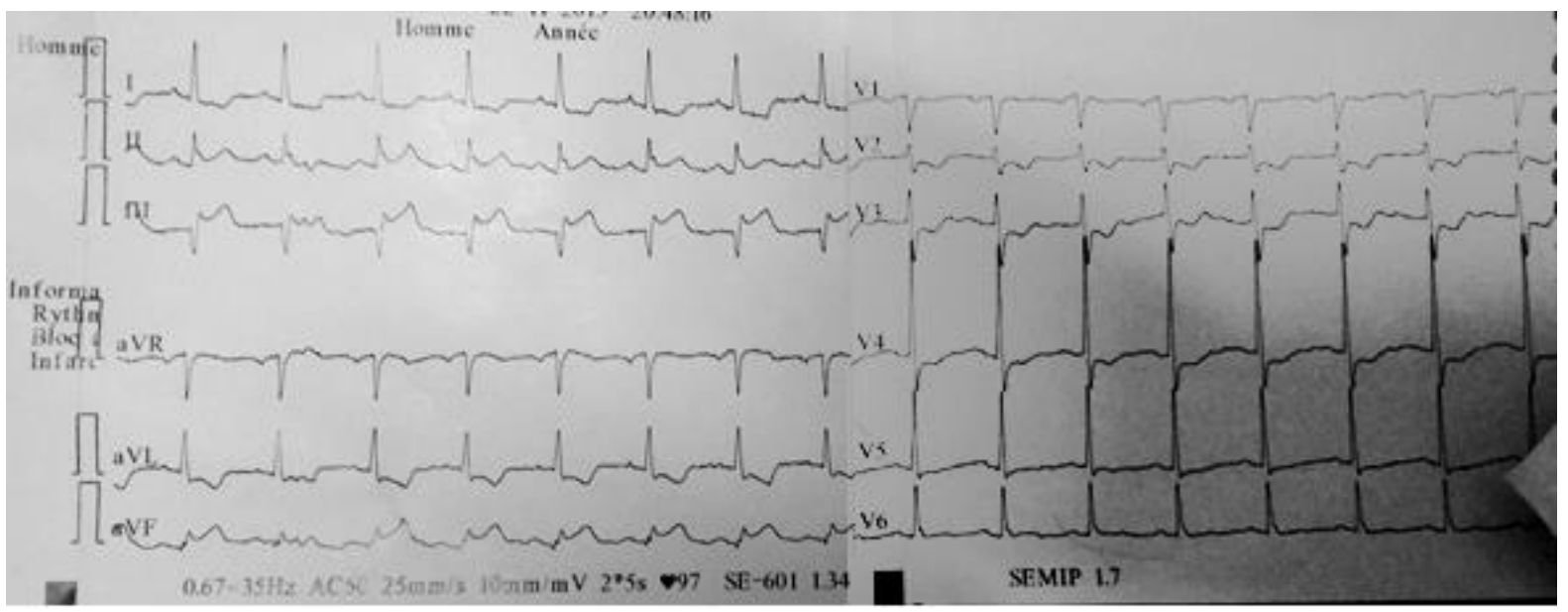

Figure 1. (Patient's ECG): ST Elevation in Inferior Leads (II, III, AvF), ST Depression and Negative T Wave in V1 V2 V3 and I, AvL.

Within $24 \mathrm{~h}$ chest pain resolved, body temperature remained between 35.6 and 37.5; ECG showed a mild regression of the ST-segment elevation with $\mathrm{T}$ wave inversion on the same territory. Cardiac MRI (Fig 2) was performed showing $\mathrm{T} 2$ signal enhancement and late gadolinium enhancement in the subepicardial inferior wall which confirmed the diagnosis of acute myocarditis.

The patient was discharged one week later with antiinflammatory treatment, ramipril $5 \mathrm{mg}$ and bisoprolol $2.5 \mathrm{mg}$ with continuous pain sedation.

A post-discharge one month follow-up visit showed that the patient was recovering well, with normalization of ECG, and echography parameters.

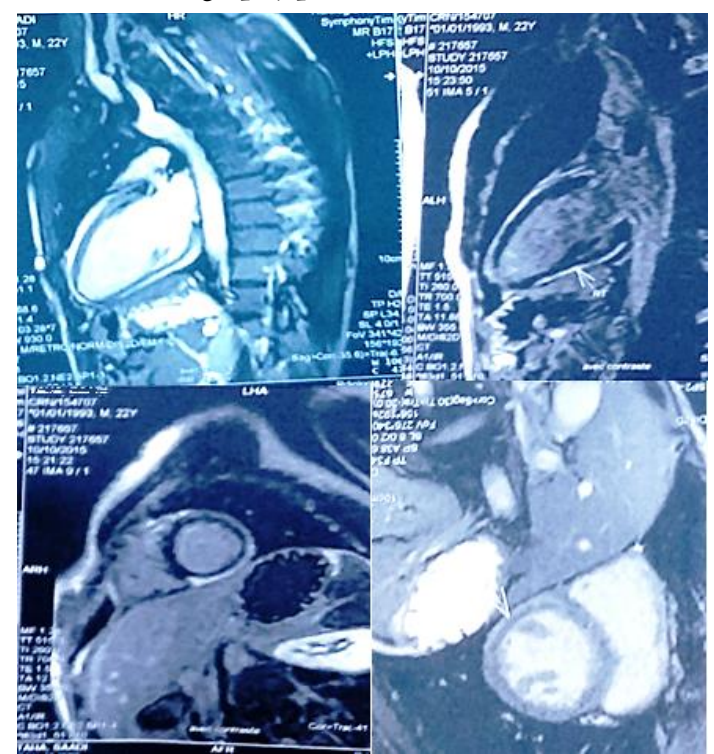

Figure 2. (Cardiac MRI): Enhanced Signal Intensity in T2-weighted Sequences which Translate Subepicardial edema; Late Gadolinium Enhancement LGE: High Signal Intensity (Late Enhancement) in Epicardial Regions with Respect of Endocardium.

\section{DISCUSSION}

The diagnosis of myocarditis is challenging, due to the variability of symptoms that are often unspecific, ranging from asymptomatic to life-threatening.
Clinical suspicion is based mainly on a medical history of flu-like signs as mild fever, myalgia, and nausea, one to three weeks before the other symptoms, and regressing spontaneously afterwards [3]. Few patients can develop retrosternal chest pain that can mimic acute coronary syndrome, shortness of breath, arrhythmia or even inaugural acute heart failure, which may require hospitalization.

The difficulty of diagnosis in Myocarditis lies in the lack of established non-invasive gold standard confirmation test. As the endomyocardial biopsy (EMB) is the current invasive gold standard [4], it has a relatively low sensitivity due to the variability in interpretation and sampling error [5].

ECG often displays some abnormalities, $-\mathrm{T}$ wave changes, ST elevation, atrial and ventricular arrhythmias, atrioventricular conduction defects, or blocks [6]. Nonetheless, these findings remains nonspecific and may be present in various conditions.

Cardiac troponin is often elevated in the acute phase of Myocarditis [7]. However, as electrocardiogram, Troponins levels are non-specific for myocarditis.

Echocardiography might be useful to myocarditis diagnosis; it can show left ventricular dilation, decreased systolic and / or diastolic function, and localized wall motion abnormalities, even though these findings could be found during myocardial infarction [8].

The indication of coronary angiography remains justified, when the SCA chart is complete, so as not mislead an occlusion of epicardial coronary artery

Due to a lack of specificity of clinical signs, many diagnoses should be considered as differential diagnoses, including Acute Coronary Syndromes (coronary spasm, myocardial infarction or ischemia; unstable angina). Pericarditis and Pericardial effusion should be considered as a differential diagnoses. Recently, MRI has become the best non-invasive modality of diagnoses objectiving the presence of infiltrates characterized by areas of enhancement (late gadolinium enhancement) on approximately 10 minutes of gadolinium administration with a patchy or 
multifocal pattern correlating well with regions of histologically proven myocarditis

More importantly, cardiac MRI can help differentiate myocarditis from ischemic cardiomyopathy. As ischemic cardiomyopathy tend to display endocardium damage with edema and enhancement localized the culprit vessel territory whereas a case of myocarditis would present as a characteristic epicardial and myocardial involvement sparing endocardium [9]. cMRI can also provide a prognosis clue. As it appears that contrast enhancement ratio at four weeks was predictive of the functional and clinical long-term outcome in myocarditis patients [10]. Treatment of myocarditis is primarily supportive but should bear in mind to treat any identifiable cause.

Patients who experience heart failure should receive angiotensin-converting enzyme inhibitors or angiotensin II receptor blockers, beta-blockers, and diuretics if needed. Dysrhythmias may be seen with or without left atrial or ventricular thrombus that may require anticoagulation [11].

Even though the causal agent is often viral, antiviral therapy is not recommended, and non-steroid antiinflammatory agents should be avoided in the acute setting as they may impair healing of the myocardium. Regular consultations as a follow-up should be planned with repeated echocardiography [12].

\section{CONCLUSION}

The pseudo-infarction forms of acute myocarditis are less known. The differential diagnosis remains difficult despite advances in exploration methods noninvasive, in particular, MRI which constitutes the first diagnostic means currently. The interest of early diagnosis and treatment adapted to the etiology on the acute phase of the myocarditis enhances prognosis.

\section{Conflict of Interests}

The authors declare that they have no conflict of interests

\section{REFERENCES}

1. Feldman AM, McNamara D. Myocarditis. N Engl J Med. 2000;343(19):1388-98.

10.1056/NEJM200011093431908 pmid: 11070105
2. Lieberman EB, Hutchins GM, Herskowitz A, Rose NR, Baughman KL. Clinicopathoiogic description of myocarditis. J Am Coll Cardiol. 1991;18(7):1617-26. doi: 10.1016/07351097(91)90493-s

3. Mamas MA, Fraser D, Neyses L. Cardiovascular manifestations associated with influenza virus infection. Int J Cardiol. 2008;130(3):304-9. doi: 10.1016/j.ijcard.2008.04.044 pmid: 18625525

4. Cooper LT, Baughman KL, Feldman AM, Frustaci A, Jessup $\mathrm{M}, \mathrm{Kuhl} \mathrm{U}$, et al. The role of endomyocardial biopsy in the management of cardiovascular disease: a scientific statement from the American Heart Association, the American College of Cardiology, and the European Society of Cardiology Endorsed by the Heart Failure Society of America and the Heart Failure Association of the European Society of Cardiology. J Am Coll Cardiol. 2007;50(19):1914-31.

5. O'Connell JB, Henkin RE, Robinson JA, Subramanian R, Scanlon PJ, Gunnar RM. Gallium-67 imaging in patients with dilated cardiomyopathy and biopsy-proven myocarditis. Circulation. 1984;70(1):58-62. doi: 10.1161/01.cir.70.1.58 pmid: 6586327

6. Morgera T, Di Lenarda A, Dreas L, Pinamonti B, Humar F, Bussani R, et al. Electrocardiography of myocarditis revisited: clinical and prognostic significance of electrocardiographic changes. Am Heart J. 1992;124(2):455-67. doi: 10.1016/0002-8703(92)90613-z pmid: 1636589

7. Felker GM, Boehmer JP, Hruban RH, Hutchins GM, Kasper EK, Baughman KL, et al. Echocardiographic findings in fulminant and acute myocarditis. J Am Coll Cardiol. 2000;36(1):227-32. doi: 10.1016/s0735-1097(00)00690-2 pmid: 10898439

8. Hsiao JF, Koshino Y, Bonnichsen CR, Yu Y, Miller FA, Jr., Pellikka PA, et al. Speckle tracking echocardiography in acute myocarditis. Int J Cardiovasc Imaging. 2013;29(2):275-84. doi: 10.1007/s10554-012-0085-6 pmid: 22736428

9. Mahrholdt H, Goedecke C, Wagner A, Meinhardt G, Athanasiadis A, Vogelsberg H, et al. Cardiovascular magnetic resonance assessment of human myocarditis: a comparison to histology and molecular pathology. Circulation. 2004;109(10):1250-8. 10.1161/01.CIR.0000118493.13323.81 pmid: 14993139

10. Wagner A, Schulz-Menger J, Dietz R, Friedrich MG. Longterm follow-up of patients paragraph sign with acute myocarditis by magnetic paragraph sign resonance imaging. MAGMA. 2003;16(1):17-20. doi: 10.1007/s10334-0030007-7 pmid: 12695882

11. Maisch B, Alter P. Treatment options in myocarditis and inflammatory cardiomyopathy : Focus on i.v. immunoglobulins. Herz. 2018;43(5):423-30. doi: 10.1007/s00059-018-4719-x pmid: 29947834

12. Maron BJ, Ackerman MJ, Nishimura RA, Pyeritz RE, Towbin JA, Udelson JE. Task Force 4: HCM and other cardiomyopathies, mitral valve prolapse, myocarditis, and Marfan syndrome. J Am Coll Cardiol. 2005;45(8):1340-5. doi: 10.1016/j.jacc.2005.02.011 pmid: 15837284 